\title{
SPORTS ANTHROPOLOGICAL INVESTIGATION OF MALE BASKETBALL PLAYERS OF DIFFERENT PERFORMANCE CLASSES
}

\author{
Christoph Raschka, Thorsten Müller, Alexander Ludwig \\ Institute of Sports Sciences, Julius Maximilians University Würzburg, Germany
}

\begin{abstract}
The present study focused on somatotypical and sports anthropological differences in German basketball players of different position and performance classes. German basketball players $(n=64)$ from Hesse and North Rhine-Westphalia (the mean age $26.8 \pm 6.3$ years) were divided by league affiliation in 3 pools (2./3. Division, 4./5. Division and 6./7. Division) and differentiated to their positions (center, winger, guards). They were measured according to the standardized guidelines of sports anthropology. The body height of the pool 1 guards averaged $187.2 \pm 5.3 \mathrm{~cm}$, the body height of the center players $205.4 \pm 5.7$ $\mathrm{cm}$, and the body height of the wingers $191.5 \pm 4.7 \mathrm{~cm}(\mathrm{p}<0.001$ relative to the position, $\mathrm{p}<0.01$ with respect to the performance level). Calipermetry showed a significantly higher percentage of the body fat of the lower divisions. In the top divisions, the body fat percentages were $13.2 \%$ for the guards, $20 \%$ for the centers and $18.3 \%$ for the wingers $(\mathrm{p}<0.001)$.

The mean somatotypes were $4.0-4.4-2.8$ for all the guards, $5.7-4.5-2.5$ for all the center players and $4.5-4.5-2.6$ for all the wingers.

Today's German basketball players are tall and leggy. The athletes of the middle and lower levels have a higher fat content. With respect to the playing position the guards are relatively smaller players with the lower percentage of body fat. The center players show the highest body weight and the body height dimensions, wherein the wingers are classified as player somatotypes therebetween.
\end{abstract}

Keywords: sports anthropological investigation, male basketball players 


\section{INTRODUCTION}

Basketball is played by 2 teams of 5 players on a rectangular court. Because many techniques for shooting, passing, dribbling and rebounding were developed, in basketball specialized player positions and offensive and defensive structures (player positioning) can be differentiated. Typically, the tallest members of a team play "center", "power forward" or "small forward" positions, while shorter players or those who possess the best ball handling skills and speed play "point guard" or "shooting guard".

The present study focused on somatotypical and sports anthropological differences in German basketball players of different position and performance classes.

\section{PARTICIPANTS AND METHODS}

According to their league affiliation $n=64$ German basketball players from Hesse and North Rhine-Westphalia (the mean age 26.8 \pm 6.3 years) were divided by league affiliation in 3 pools (2./3. Division, 4./5. Division and 6./7. Division) and differentiated to their positions (center, winger, guards, Table 1).

They were measured according to the standardized guidelines of sports anthropology (Raschka 2006). For somatotyping the established typologies of Conrad \& Heath / Carter (see Raschka 2006) were used. Body fat was determined calipermetrically according to Parizkova and Buzkova (1971).

Table 1. Compilation of basketball players by position and league

\begin{tabular}{llcccc}
\hline Pool/Division & & Center & Winger & Guard & Sum \\
\hline \multirow{2}{*}{ Pool1 } & Second Division & 2 & 5 & 3 & $\mathbf{1 0}$ \\
\cline { 2 - 6 } & Third Division & 2 & 4 & 1 & $\mathbf{7}$ \\
\hline \multirow{2}{*}{ Pool2 } & Fourth Division & 1 & 1 & 0 & $\mathbf{2}$ \\
\cline { 2 - 6 } & Fifth Division & 6 & 6 & 2 & $\mathbf{1 4}$ \\
\hline \multirow{2}{*}{ Pool3 } & Sixth Division & 7 & 7 & 4 & $\mathbf{1 8}$ \\
\cline { 2 - 6 } & Seventh Division & 4 & 6 & 3 & $\mathbf{1 3}$ \\
\hline & & $\mathbf{2 2}$ & $\mathbf{2 9}$ & $\mathbf{1 3}$ & $\mathbf{6 4}$ \\
\hline
\end{tabular}

\section{RESULTS}

The athletes of the highest performance levels dominated with all height parameters (Figure. 1). 


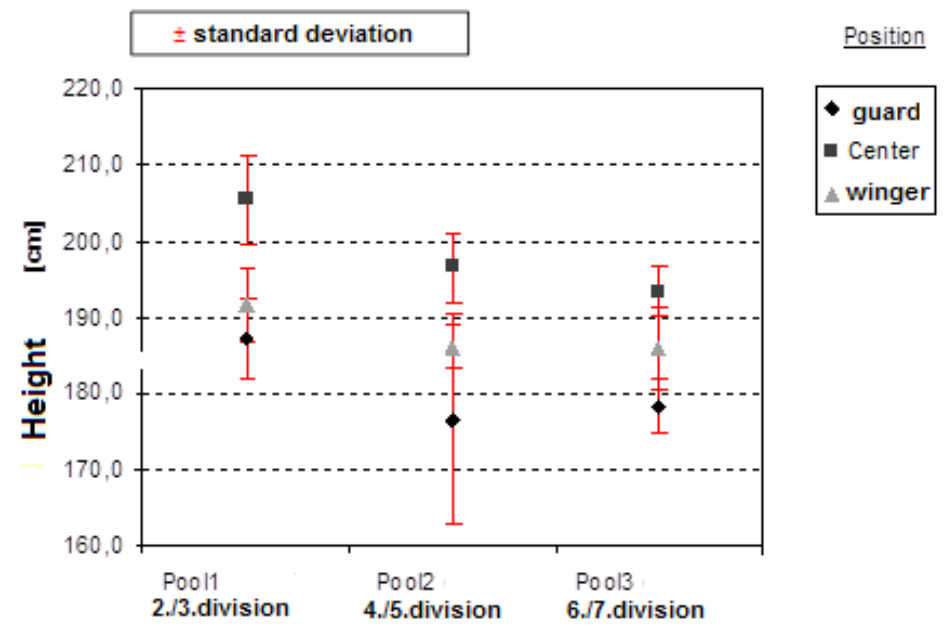

Figure 1. Means and standard deviations of the body height of the basketball players, differentiated by the level of performance and position

Thus, the body height of the pool 1 point and shooting guards averaged $187.2 \pm 5.3 \mathrm{~cm}$, the body height of the center players $205.4 \pm 5.7 \mathrm{~cm}$, and the body height of the wingers $191.5 \pm 4.7 \mathrm{~cm}$ ( $\mathrm{p}<0.001$ relative to the position, $\mathrm{p}<0.01$ with respect to the performance level).

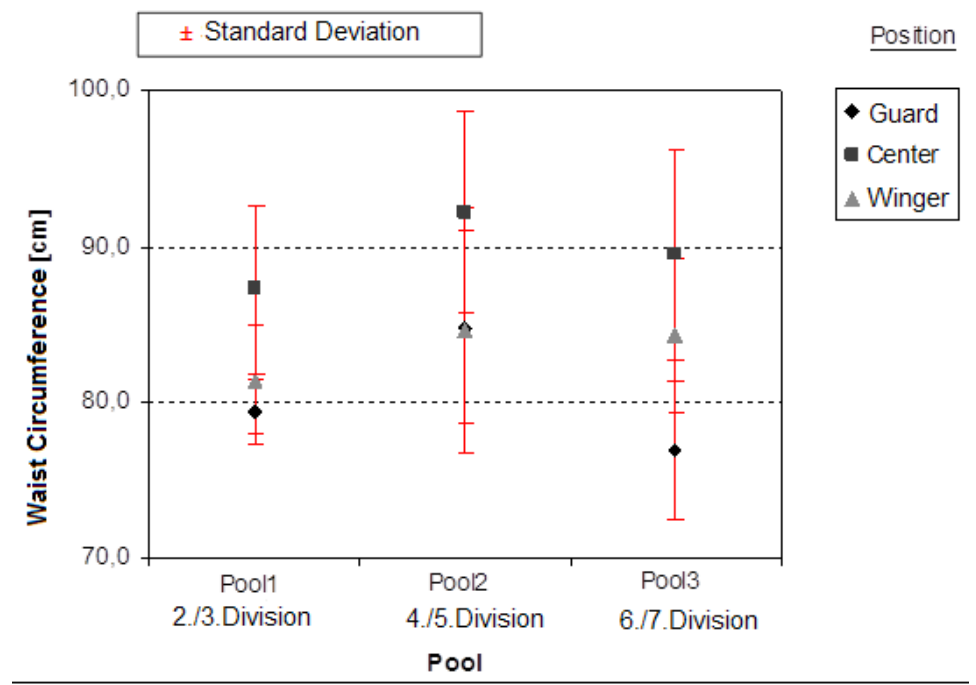

Figure 2. Means and standard deviations of the waist circumferences of the basketball players, differentiated by the level of performance and position. 
Regarding the performance levels, significantly higher waist circumferences (Figure. 2) were found in the players of Pool 2 and Pool 3 in terms of a higher subcutaneous fat share $(\mathrm{p}<0.05)$.

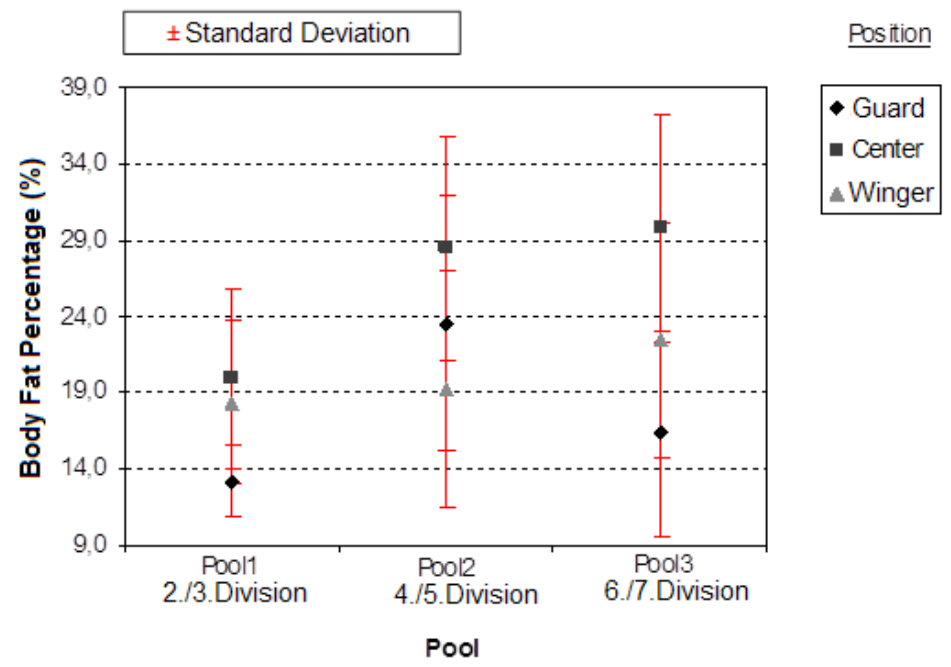

Figure 3. Means and standard deviations of the Body Fat Percentage, determined according to the methodology of Parizkova \& Buzkova (1971, calipermetrically), of the basketball players, differentiated by the level of performance and position.

These findings are also supported by a significantly higher percentage of body fat (Figure 3) of the lower divisions.

In the top divisions, the body fat percentages were $13.2 \%$ for the guards, $20 \%$ for the centres and $18.3 \%$ for the wingers $(p<0.001)$.

Further confirmation is given by the higher Suprailiacal skinfold values (Figure 4) of the lower divisions.

In the chessboard pattern graph after Conrad the metric (plastic) Index averages (Figure. $5+6$ ) are for any guards at -0.8 / Class $\mathrm{G}(84 /$ Class 5), for the wingers at -0.7 / Class F ( 85.6 / Class 5$)$ and for the Centers at 0.6 / class F (88/Class 6).

In the somatochart of Heath \& Carter (Fig. 7) there was a slight focusing of the basketball somatotypes in the mesoendomorph as well as in the endomesomorph sixth. The mean somatotypes were $4.0-4.4-2.8$ for all the guards, $5.7-4.5-2.5$ for all the center players and $4.5-4.5-2.6$ for all the wingers. 


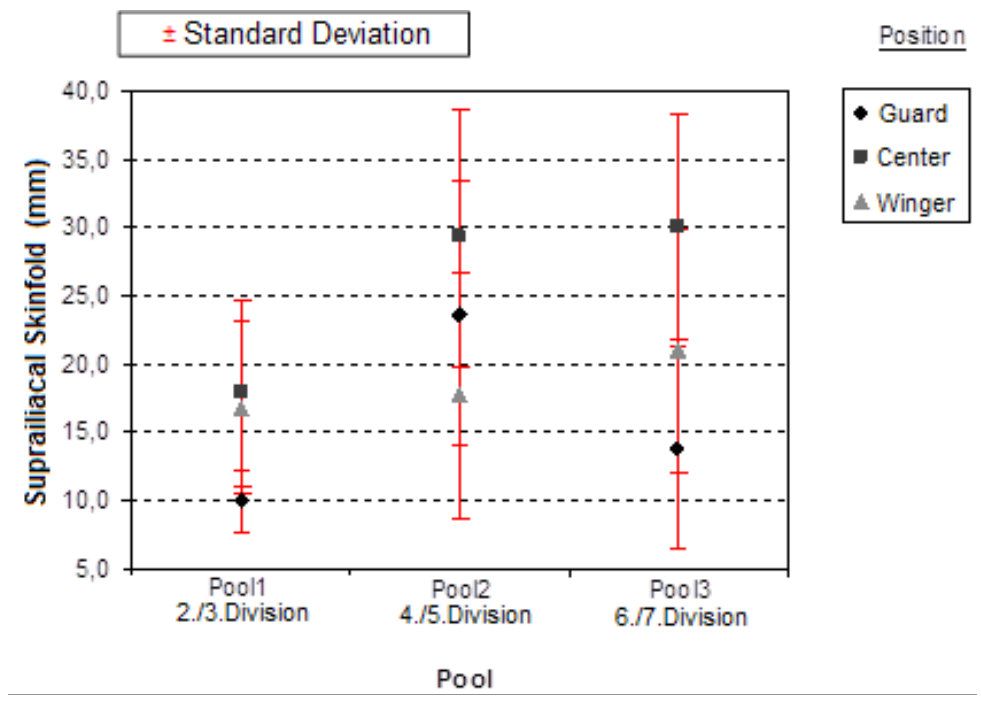

Figure 4. Means and standard deviations of the Suprailiacal Skinfold of the basketball players, differentiated by the level of performance and position

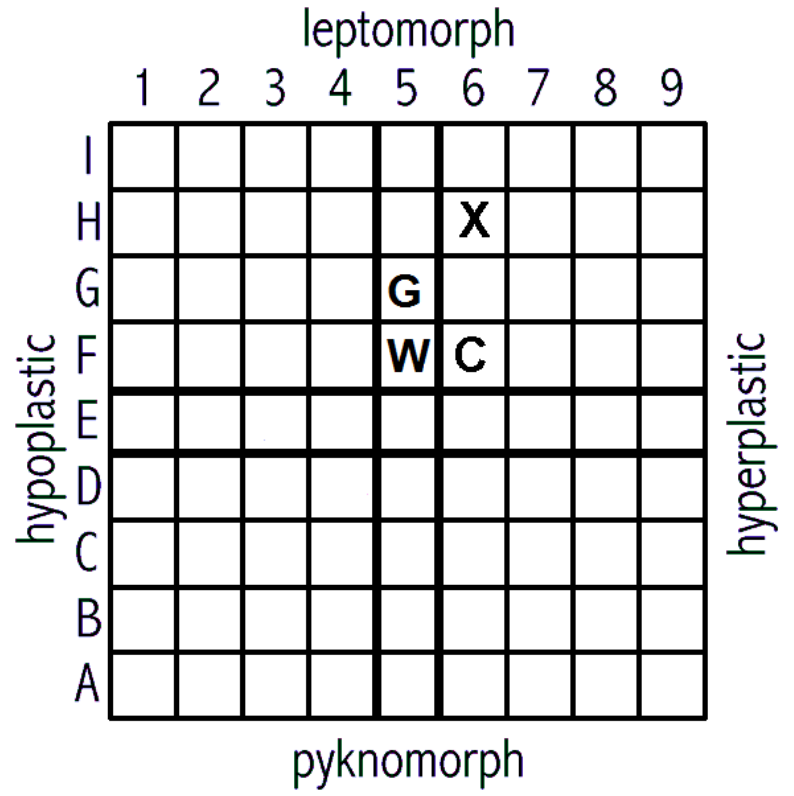

Figure 5. Mean Constitution Type of Guards (G), Wingers $(W)$ and Centers (C) of this Germany study, compared to East German basketball players (X) according to Tittel / Wutscherk (1972) 


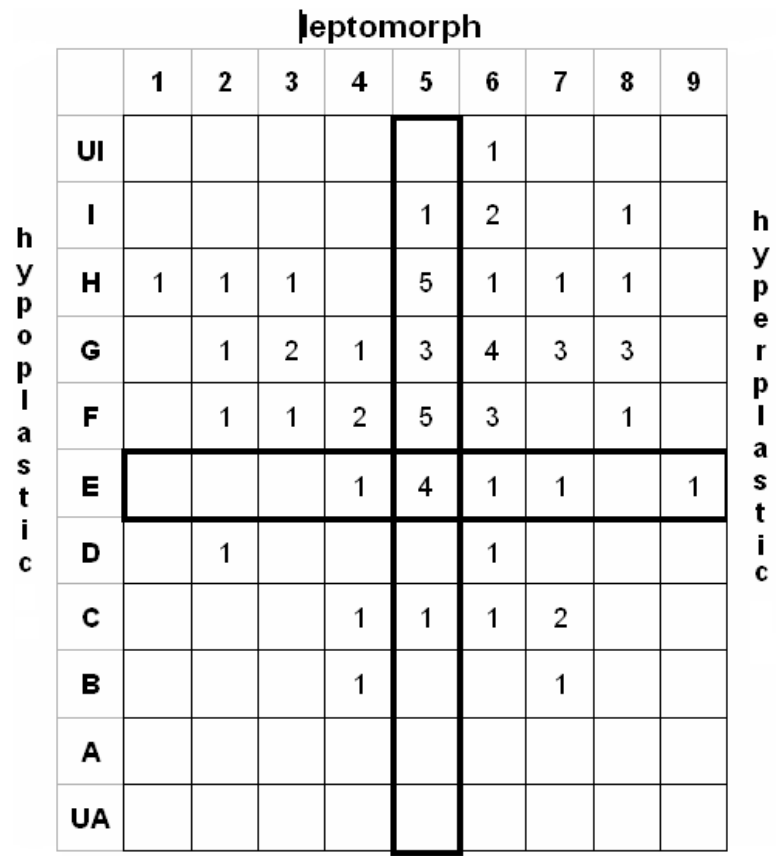

pyknomorph
Figure 6. Constitution type distribution by Conrad for all the studied basketball players $(n=64)$

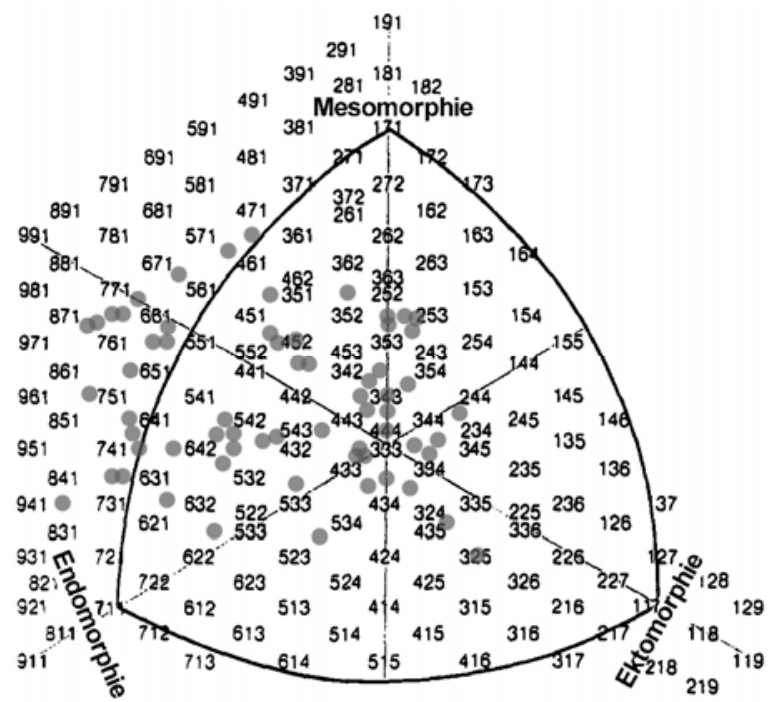

Figure 7. Distribution of all the Basketball somatotypes in the somatochart according to Heath \& Carter 
For pool 1 the average somatotype was $3.9-4.0-3.2$, for pool $25.0-4.9-2.4$, and for pool $35.2-4.5-2.4$. While inference analytically there were not any significant somatotypical differences concerning the position or performance levels for the differences in mesomorphy, there was a (very) significant influence of the performance level on differences in endomorphy or ectomorphy.

With respect to the position, only the differences in endomorphy are very significant.

\section{DISCUSSION}

Today's German basketball players (Figure 8) are tall and leggy. In contrast to previous surveys they are not very slender. The athletes of the middle and lower levels have a higher fat content. With respect to the playing position the point guards and the shooting guards are characterized as relatively smaller players with the lower percentage of body fat. By contrast, the center players show the highest body weight and body height dimensions, wherein the wingers are classified as player somatotypes therebetween.

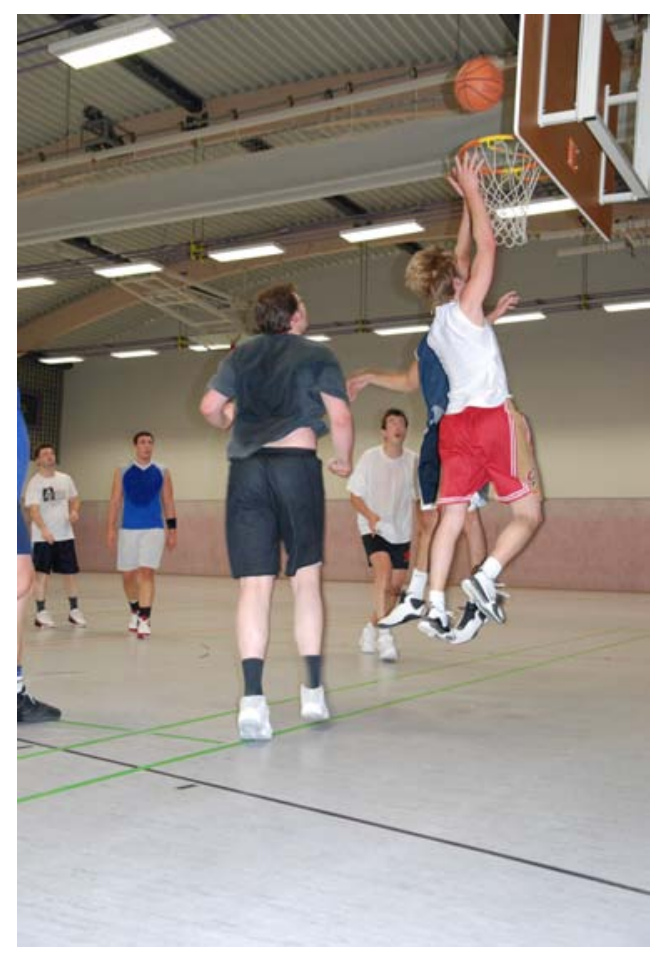

Figure 8. Basketball Players in action 
Compared to the reference studies on somatotyping of basketball players, the population studied shows significant differences especially in the first component (endomorphy).

Table 2. Comparison of International Investigations on Basketball Average Somatotypes

\begin{tabular}{llll}
\hline Authors & $\mathbf{n}$ & Specification & $\begin{array}{c}\text { Average } \\
\text { somatotype }\end{array}$ \\
\hline Carter 1970 & 8 & USSR & $2.9-4.6-2.6$ \\
\hline Carter 1984 & 68 & Olympic Athletes (Montreal \& Mexico) & $2.0-4.2-3.5$ \\
\hline Bale 1986 & 5 & British sports students & $2.5-4.7-3.6$ \\
\hline Štěpniča 1977 & 31 & Czechoslovak athletes & $2.0-5.5-3.1$ \\
\hline Viviani et al. 1991 & 11 & Italian professional basketball players & $2.6-3.6-3.3$ \\
\hline Mészáros et al. 1982 & 36 & $\begin{array}{l}\text { Hungarian high-performance athletes } \\
\text { 1972-1975 }\end{array}$ & $2.3-3.9-4.0$ \\
\hline Mészáros et al. 1982 & 22 & $\begin{array}{l}\text { Hungarian high-performance athletes } \\
\text { 1979-1980 }\end{array}$ & $2.4-4.8-3.4$ \\
\hline Raschka et al. 2013 & 64 & total German collective & $4.8-4.5-2.6$ \\
\hline Raschka et al. 2013 & 13 & all German point guards/shooting guards & $4.0-4.4-2.8$ \\
\hline Raschka et al. 2013 & 22 & all German center players & $5.7-4.5-2.5$ \\
\hline Raschka et al. 2013 & 29 & all German wingers & $4.5-4.5-2.6$ \\
\hline Raschka et al. 2013 & 17 & Pool 1 (2 ${ }^{\text {nd }}$ and 3d division, Germany) & $3.9-4.0-3.2$ \\
\hline Raschka et al. 2013 & 16 & Pool 2 (4 ${ }^{\text {th }}$ and $5^{\text {th }}$ division, Germany) & $5.0-4.9-2.4$ \\
\hline Raschka et al. 2013 & 31 & Pool 3 (6 $6^{\text {th }}$ and $7^{\text {th }}$ division, Germany) & $5.2-4.5-2.4$ \\
\hline & & &
\end{tabular}

\section{REFERENCES}

1. Bale P. (1986). The relationship of somatotype and body composition to strength in a group of men and women sport science students. In: Day J. A. P. (Ed.): Perspectives in Kinanthropometry. Champaign, Illinois, 187-198.

2. Carter J. E. L. (1970). The somatotypes of athletes - a review. Hum Biol 42, 535-569.

3. Carter J. E. L. (1984). Somatotypes of Olympic athletes from 1948 to 1976. Medicine and Sport Science 18, 80-109.

4. Conrad K. (1963). Der Konstitutionstypus. Berlin. Springer Verlag

5. Heath B. H., Carter L. J. E. (1967). A modified somatotype method. Am J Phys Anthrop 27, 57-74.

6. Heath B. H., Carter L. J. E. (1990). Somatotyping-development and applications. Cambridge Studies in Biological Anthropology. Great Britain. Redwood Press.

7. Knußmann R. (1996). Vergleichende Biologie des Menschen. Lehrbuch der Anthropologie. Stuttgart. Gustav Fischer Verlag. 
8. Kretschmer E. (1921). Körperbau und Charakter. Berlin. Springer Verlag.

9. Martin R., Knussmann R. (1988). Anthropologie. Handbuch. Band I. Stuttgart. Fischer Verlag

10. Mészáros J., Mohácsi J. (1982). An anthropometric study of top level athletes in view of the changes that took place in the style of some ball games. Humanbiologia Budapestinensis 13, 15.

11. Parizkova J., Buzkova P. (1971). Relationship between skinfold thickness measured by Harpenden Caliper and densitometric analysis of total body fat in men - a methodological contribution to the international biological program. Human Biology 43, 16-21.

12. Parnell R. W. (1954) Somatotyping by physical anthropometry. Am J Phys Anthrop 12, 209-239.

13. Raschka C. (2006). Sportanthropologie. Köln: Sportverlag Strauß.

14. Štěpniča J. (1977). Somatotypes of Czechoslovak Athletes. In: Eiben O.G. (Ed.) Growth and Development: Physique. Académiai Kiadó, Budapest. Symp Biol Hung 20, 357-364.

15. Tittel K., Wutscherk H. (1972). Sportanthropometrie. Leipzig. Barth.

16. Viviani F., Casagrande G. (1991). Il somatotipo in aleti italiani (dati preliminari). 155 UAI, FIAI (Eds.). Sommari dei Constributi Scientifici. IX. Congresso degli Antropologi Italiani, Adriatica Editrice, Bari.

\section{Adress for correspondence}

Christoph Raschka

Institute of Sports Sciences, Julius-Maximilians-University

Judenbühlweg 11, D-97082 Würzburg, Germany

E-mail: christoph.raschka@uni-wuerzburg.de 